\title{
Cancer metabolism in gastrointestinal cancer
}

\author{
Hiroshi Sawayama ${ }^{1}$, Nobutomo Miyanari' ${ }^{1}$, Hideo Baba ${ }^{2}$ \\ ${ }^{1}$ Department of Surgery, National Hospital Organization Kumamoto Medical Center, 1-5 Ninomaru, Kumamoto 860-0008, Japan. \\ ${ }^{2}$ Department of Gastroenterological Surgery, Graduate School of Medical Sciences, Kumamoto University, 1-1-1 Honjo, Kumamoto 860-8556, \\ Japan.
}

Correspondence to: Prof. Hideo Baba, Department of Gastroenterological Surgery, Graduate School of Medical Sciences, Kumamoto University,

1-1-1 Honjo, Kumamoto 860-8556, Japan. E-mail: hdobaba@kumamoto-u.ac.jp

\section{A B S T R A C T}

Cancer cells exhibit altered glucose metabolism, mitochondrial dysfunction, anaerobic glycolysis and upregulation of the pentose phosphate pathway (PPP). Recent genetic and metabolic analyses have provided insights into the molecular mechanisms of genes that are involved in the alteration of cancer metabolism and tumorigenesis. Hypoxic induced factor 1 regulates the reciprocal relationship between glycolysis and oxidative phosphorylation, and p53 also modulates the balance between the glycolytic pathway and oxidative phosphorylation. Mitochondria function in cancer differs from that in normal cells owing to mutations of mitochondrial DNA and alterations of metabolism. Overexpression of transcription factors, metabolite transporters and glycolytic enzymes is observed and associated with poor prognosis, and it may be associated with chemoradiotherapy resistance in multiple cancer cell types. The PPP plays a critical role in regulating cancer cell growth by supplying cells with ribose-5-phosphate and nicotinamide adenine dinucleotide phosphate for detoxification of intra-cellular reactive oxygen species (ROS), reductive biosynthesis and ribose biogenesis. ROS levels increase during carcinogenesis owing to metabolic aberrations. This review discusses alterations of mitochondrial metabolism, anaerobic glycolysis, the PPP and control of ROS levels by the endogenous anti-oxidant system in cancer, as well as the novel small molecules targeting these enzymes or transporters that exert anti-proliferative effects.

Key words: Anti-oxidants, cancer metabolism, mitochondria, pentose phosphate pathway, reactive oxygen species, Warburg effect

\section{Introduction}

In 1926, Otto Warburg found the conversion of glucose to lactic acid in the presence of adequate oxygen as a specific metabolic abnormality of cancer cells. $^{[1,2]}$ Warburg further hypothesized that cancer results from a defect of mitochondrial metabolism that leads to aerobic glycolysis. The role of dysfunctional glucose metabolism in cancer is now firmly established. Recent genomic and proteomic research has provided insights into the molecular mechanisms of cancer metabolism.

Two main pathways generate adenosine triphosphate (ATP) required for cell proliferation and survival. The first is glycolysis, which metabolizes glucose to pyruvate in the cytoplasm to produce a net two ATP molecules from each glucose molecule. The other is the tricarboxylic acid (TCA) cycle, which uses pyruvate formed from glycolysis to donate electrons via nicotinamide adenine dinucleotide (NADH) (reduced form of $\mathrm{NADH}$ ) and

\begin{tabular}{|l|l|}
\hline \multicolumn{2}{|c|}{ Access this article online } \\
\hline Quick Response Code: & Website: \\
\hline & www.jcmtjournal.com \\
\hline
\end{tabular}

flavin adenine dinucleotide (FADH2) (reduced form of FADH2) to the respiratory chain complexes in mitochondria. The electron transfer system generates 36 ATP molecules per glucose across the mitochondrial inner membrane. Under limited oxygen conditions, such as muscles under prolonged exercise, pyruvate is not used in the TCA cycle and is converted into lactic acid by lactate dehydrogenase $(\mathrm{LDH})$ in a process termed anaerobic glycolysis.

Recent genetic and metabolic analyses have provided insights into the molecular mechanisms of the genes that contribute to anaerobic glycolysis and tumorigenesis. The direct mechanistic links between activated oncogenes and altered glucose metabolism are regulated by phosphoinositide 3-kinase (PI3K), ${ }^{[3]} \mathrm{Akt}^{[4]} \mathrm{p} 53,{ }^{[5,6]}$ AMP-activated protein kinase (AMPK), ${ }^{[3,7]} \mathrm{c}-\mathrm{Myc}$ and hypoxia-inducible factor (HIF). The c-Myc and HIF-1A transcription factors target many of the same glycolytic enzyme genes, including hexokinase 2 (HK2),

This is an open access article distributed under the terms of the Creative Commons Attribution-NonCommercial-ShareAlike 3.0 License, which allows others to remix, tweak, and build upon the work non-commercially, as long as the author is credited and the new creations are licensed under the identical terms.

For reprints contact: reprints@ @medknow.com

How to cite this article: Sawayama H, Miyanari N, Baba H. Cancer metabolism in gastrointestinal cancer. J Cancer Metastasis Treat 2015;1:172-82.

Received: 13-07-2015; Accepted: 29-07-2015. 
pyruvate kinase type M2 (PKM2), LDH-A and pyruvate dehydrogenase kinase, isozyme 1 (PDK-1).

The pentose phosphate pathway (PPP) is a major pathway for glucose catabolism. The PPP directly or indirectly provides reducing power to fuel the biosynthesis of lipids and nucleotides and sustains anti-oxidant responses to support cell survival and proliferation. Abnormal respiratory metabolic pathways influence energy balance and the reactive oxygen species (ROS) balance in cancer cells. The increase in ROS generation from metabolic abnormalities and oncogenic signaling in cancer cells triggers a redox adaptation response to maintain ROS levels below the toxic threshold. Cancer cells would be increasingly dependent on the anti-oxidant system.

In this review, significant molecular insights into mitochondrial metabolism, anaerobic glycolysis and the PPP in cancer are discussed. We also review the control of ROS levels by the endogenous anti-oxidant system and the therapeutic strategies targeting cancer metabolism.

\section{Mitochondria in Cancer Cells}

As the main energy producers, mitochondria produce ATP using the TCA cycle and oxidative phosphorylation. However, they also generate ROS during this process, which are harmful to the cell if produced in excess. In addition, mitochondria play a crucial role in the regulation of cell death pathways and intra-cellular $\mathrm{Ca}^{2+}$ homeostasis. Mitochondria activate apoptosis by regulating the release of pro-apoptotic proteins from the mitochondrial intermembrane to the cytosol, and they also play a crucial role in non-apoptotic cell death. ${ }^{[8]}$ Key regulators related to cell death in the mitochondria are frequently altered in cancer cells, ${ }^{[9]}$ and the function of mitochondria in cancer cells is different from that in normal cells. ${ }^{[10]}$

The mitochondrial mechanism in cancer cells is different from that in normal cells using oxidative phosphorylation. In oxidative phosphorylation, ATP synthesis requires significant amounts of oxygen, which leads to the continuous production of ROS such as superoxide anion, organic peroxide and hydrogen peroxide. ${ }^{[11]}$ If the redox regulating system does not eliminate the generated ROS, the excessive ROS may cause cellular damage. Mitochondria have redox defense systems for the elimination of hydrogen peroxide. Glutathione (GSH) and glutathione peroxidases require nicotinamide adenine dinucleotide phosphate (NADPH) for the elimination of $\mathrm{H}_{2} \mathrm{O}_{2}$ and other peroxides generated in the mitochondria. The mitochondrial complex V (ATP synthase) produces ATP from ADP and inorganic phosphate. As an anti-oxidant defense system, peroxiredoxin (Prx) 3, Prx5, superoxide dismutase 2 (SOD2) and thioredoxin 2 eliminate ROS produced in mitochondria. ${ }^{[12,13]} \operatorname{Prx} 3$ knockout $(\mathrm{KO})$ mice exhibit metabolic dysregulation and induction of oxidative damage, ${ }^{[14]}$ thioredoxin $2 \mathrm{KO}$ mice show an embryonic lethal phenotype ${ }^{[15]}$ and SOD2 KO mice die within 3 weeks of birth because of mitochondrial oxidative damage and severe neurodegeneration. ${ }^{[16,17]}$

Mutations in mitochondrial DNA (mtDNA) occur at a high frequency in human tumors. Tumor mtDNA somatic mutations range from severe insertions/deletions and chain termination mutations to mild missense mutations. A total of 190 tumor-specific somatic mtDNA mutations have been reported and $72 \%$ of them are also mtDNA sequence variants found in the general population. They include 52\% tumor somatic mRNA missense mutations, $83 \%$ tRNA mutations, 38\% rRNA mutations and $85 \%$ control region mutations. Germline mtDNA mutations at nucleotides 10,398 and 16,189 have been associated with breast cancer, ${ }^{[18]}$ esophageal cancer ${ }^{[19]}$ and endometrial cancer. ${ }^{[20]}$ The mtDNA conferring high metastatic potential contained G13997A and 13885insC mutations in the gene encoding $\mathrm{NADH}$ dehydrogenase sub-unit 6. These mutations produced a deficiency in respiratory complex I activity and were associated with overproduction of ROS. ${ }^{[21]}$ Severe mutations can inhibit oxidative phosphorylation, increase ROS production and promote tumor cell proliferation; milder mutations may permit tumors to adapt to new environments. ${ }^{[22]}$

Recent investigations have revealed that p53 can modulate the balance between the glycolytic pathway and mitochondrial oxidative phosphorylation. ${ }^{[23]}$ The key component in this regulation is the gene encoding synthesis of cytochrome c oxidase 2 (SCO2), in conjunction with the SCO1 protein. Analysis of potential p53 target genes that can influence mitochondrial function showed that $\mathrm{SCO} 2$, but not SCO1, was induced in a p53-dependent manner. $\mathrm{SCO} 2$ is critical for regulating the cytochrome c oxidase (COX) complex, the major site of oxygen use and is required for the assembly of COX. ${ }^{[24]}$ Mutation of p53 in tumor cells leads to inhibition of mitochondrial respiration as a result of COX deficiency and a shift of cellular energy metabolism toward glycolysis. Inhibition of glycolysis by glucose withdrawal leads to the activation of p53. Under conditions of cellular stress, activation of p53 could increase SCO2 expression and stimulate mitochondrial respiration and ATP production. Another newly discovered target of p53 is TP53-induced glycolysis and apoptosis regulator (TIGAR). Expression of TIGAR lowered fructose-2,6-bisphosphate levels in cells, resulting in the inhibition of glycolysis while stimulating NADPH generation through the pentose phosphate shunt. ${ }^{[25]}$ The expression of TIGAR in primary tumors is significantly correlated with standardized uptake values max, and low expression of TIGAR may predict a worse clinical outcome in patients with non-small cell lung cancer. ${ }^{[26]}$

HIF-1 plays an important role in the upregulation of enzymes stimulating glucose use. Recent investigations demonstrated that HIF-1 suppresses mitochondrial function in tumor cells and modulates the reciprocal relationship between glycolysis and oxidative 
phosphorylation. The balance between glycolysis and oxidative phosphorylation is controlled by the relative activities of two enzymes: pyruvate dehydrogenase (PDH) and LDH. The activity of PDH is negatively controlled by PDK-1, and HIF-1 can inactivate PDH by inducing PDK-1. Inactivation of PDH leads to suppression of mitochondrial respiration. ${ }^{[27,28]}$ HIF-1 also stimulates expression of LDH-A, which facilitates the conversion of pyruvate into lactate, ${ }^{[10]}$ which decreases use of pyruvate by mitochondria and suppresses mitochondrial respiration. In addition, HIF-1 can also modulate COX expression. Under hypoxic conditions, the sub-unit composition of COX is changed to optimize its activity. The expression of the COX4-2 sub-unit is increased and optimizes the activity of COX under aerobic conditions. ${ }^{[24]}$

Another important consequence of the glycolytic shift in tumor cells is their acquired resistance to apoptotic cell death. The two major apoptotic pathways include the extrinsic (receptor-mediated) pathway and the intrinsic pathway. The extrinsic pathway engages initiator pro-caspase-8, which activates pro-caspase-3 and other effector caspases. The intrinsic pathway involves permeabilization of the outer mitochondrial membrane (OMM) followed by the release of cytochrome $\mathrm{c}$ and other proteins from the intermembrane space of mitochondria. Permeabilization of the OMM is considered to be a crucial event during the early phase of the apoptotic process. Multiple proteins, including B-cell lymphoma 2 (Bcl-2) family, ${ }^{[29,30]}$ hexokinase, ${ }^{[31,32]} \mathrm{Akt}^{[33,34]}$ and loss of p53, ${ }^{[35,36]}$ support the glycolytic shift. These proteins render tumor mitochondria less susceptible to the permeabilization of the OMM and the mitochondrial pathway of apoptosis.

\section{Alteration of Protein Expression in the Warburg Effect}

Cancer cells exhibit altered glucose metabolism, which is described by the increased uptake of glucose and the conversion of glucose to lactate in cancer cells under adequate oxygen tension. HIF-1A and c-Myc transcription factors cooperatively induce a transcriptional program for glycolysis by targeting many glycolytic enzyme genes, including HK2, PKM2, LDH-A and PDK-1. Key regulatory sub-units of HIF include HIF-1A and endothelial PAS domain protein 1 (EPAS1; HIF-2), and these proteins are differentially overexpressed in cancer cells. $^{[37,38]}$ Many studies demonstrated that HIF-1A positive expression was significantly associated with poor outcome of diverse human cancers. ${ }^{[38-43]}$ Low expression of HIF-1A may be associated with a favorable outcome of 5-fluorouracil (5-FU)-based adjuvant chemotherapy in gastric cancer patients. ${ }^{[4,45]}$ High expression of HIF-2A was associated with poor survival in gastric cancer patients, ${ }^{[46]}$ but not colorectal cancer (CRC) patients. ${ }^{[42,47]}$ The MYC protein affects the expression of approximately $15 \%$ of the genes in the human genome, ${ }^{[48]}$ and thus MYC deregulation may result in alterations in various biological pathways involved in cancer initiation and progression. ${ }^{[49]}$ The expression of MYC genes is often elevated or deregulated in human neoplasms, and c-Myc seems to be at the crossroads of several important pathways and processes involved in carcinogenesis. MYC overexpression and promoter hypomethylation may have a role in the gastric carcinogenesis process. MYC deregulation was mainly associated with poor prognostic features. ${ }^{[50]}$

The GLUT family proteins are glucose transporter-like proteins that have been well characterized. The 14 GLUTs are categorized into three classes based on sequence similarity: Class 1 (GLUTs 1-4 and 14); Class 2 (GLUTs 5, 7, 9 and 11) and Class 3 (GLUTs 6, 8, 10, 12 and HMIT). ${ }^{[51]}$ Several studies have been published on GLUT family members, especially GLUT $3,{ }^{[52-54]}$ but GLUT 1 has been the main focus of the investigation. ${ }^{[55-57]}$ GLUT 1 comprises 492 amino acid residues and possesses a single $\mathrm{N}$-linked glycosylation site at $\mathrm{N} 45,{ }^{[58]}$ and its crystal structure has been reported recently. ${ }^{[59]}$ GLUT 1 is transcriptionally regulated by $\mathrm{HIF}-1 \mathrm{~A}^{[60]}$ and c-Myc. ${ }^{[61]}$ A recent investigation showed that GLUT 1 was upregulated in cells with KRAS or BRAF mutations, ${ }^{[62]}$ and GLUT 1 expression in CRC cells was positively correlated with FDG accumulation and KRAS/BRAF mutation. ${ }^{[63]}$ MAPK signaling induces phosphorylation of Ser 37 in PKM2, and nuclear-phosphorylated PKM2 then induces c-Myc expression, resulting in the upregulation of GLUT 1. ${ }^{[64]}$ Overexpression of GLUT 1 in a mammary tumor cell line with low levels of endogenous GLUT 1 results in both a decrease in apoptosis and an increase in proliferation. ${ }^{[65]}$

Hexokinases catalyze the phosphorylation of glucose to glucose-6-phosphate (G6P). This is the first and rate-limiting step in glucose metabolism. HK2 is one of four members of the hexokinase family. The hexokinase isoenzymes (HK1, HK2, HK3 and glucokinase) are structurally similar; however, only HK1 and HK2 are functionally similar. $\mathrm{HK} 2$, but not $\mathrm{HK} 1$, is overexpressed in several cancer types compared with normal tissue, and overexpression of $\mathrm{HK} 2$ was reported in hepatocellular carcinoma (HCC). ${ }^{[66-68]} \mathrm{HK} 2$ localizes to the outer membrane of the mitochondria and is the major hexokinase isoform expressed in cancer cells. ${ }^{[69]}$

PK is a glycolytic enzyme that catalyzes a reaction generating pyruvate and ATP from phosphoenolpyruvate and ADP. Four isoforms of PK (L, R, M1 and M2) are present in mammals. Splicing of PKM is regulated by splicing repressors, and the expressions of those repressors are induced by MYC oncoprotein. ${ }^{[0,71]} \mathrm{M} 2$ is expressed in embryonic cells, adult stem cells and cancer cells and is necessary for aerobic glycolysis and that this metabolic phenotype provides a selective growth advantage for cancer cells in vivo. ${ }^{[72]}$ Mutation of the S37 ERK phosphorylation site in PKM2 blocked translocation of PKM2 to the nucleus, ${ }^{[64]}$ which suggested 
that PKM2 moves into the nucleus as a monomer. Tumor cells have multiple ways to regulate PKM2 for cell growth and survival, including controlling PKM2 expression, localization, post-translational modification and allosteric regulation. PKM2 also has non-metabolic functions as a transcriptional coactivator and protein kinase. PKM2 is considered an attractive target for cancer treatment. ${ }^{[73]}$ Further studies are needed before inhibitors and activators of PKM2 can be used as therapeutic interventions. ${ }^{[74]}$

PDK regulates $\mathrm{PDH}$, which links glycolysis to the TCA cycle by reversible phosphorylation. Phosphorylation of $\mathrm{PDH}$ by PDK inactivates PDH and halts pyruvate use in the TCA cycle. ${ }^{[75]}$ Four PDK isoforms have been verified in human tissue, and the expression of these isoforms was organ specific. PDK-1 positivity was associated with poor prognosis in gastric cancer; ${ }^{[76]}$ however, expression of PDK-1 was decreased in colon cancer compared to normal tissue. PDK-3 expression was detected in colon cancer, and PDK-3 positivity was associated with poor prognosis. ${ }^{[77]}$ Only a few studies have reported the relation between PDK positivity and prognosis, and the clinical significance of PDK expression has remained unclear. $\mathrm{LDH}$ is a tetrameric enzyme comprising two major sub-units, A and/or B, resulting in five isozymes (A4, A3B1, A2B2, A1B3 and B4) that can catalyze the forward and backward conversion of pyruvate to lactate. LDH-A (LDH-5, MLDH or A4), which is the predominant form in skeletal muscle, kinetically favors the conversion of pyruvate to lactate, controlling the conversion of pyruvate to lactate of the cellular glycolytic process. ${ }^{[78]}$ Many studies have shown that human cancers have higher LDH-A levels compared with normal tissues. ${ }^{[79]}$ Previous studies showed that 661 intestinal-type gastric cancer (ITGC) $)^{[80]}$ and $128 \mathrm{CRC}^{[81]}$ specimens with high LDH-A expression are associated with poor prognosis. LDH-A is specifically phosphorylated at Y10 in various cancer cell lines, head and neck squamous cell carcinoma (SCC), lung cancer, breast cancer and prostate cancer cells and by diverse oncogenic tyrosine kinases, including FGFR1, ABL, JAK2 and FLT. ${ }^{[82]}$ LDH-A reduction using si-RNA for LDH-A can suppress the tumorigenicity of ITGC cells ${ }^{[80]}$ and HCC. ${ }^{[83]}$

\section{The Pentose Phosphate Pathway}

The PPP is a major pathway for glucose catabolism. Glucose is a common fuel for multicellular organisms, entering cells through GLUTs and then being phosphorylated by HK to form G6P. G6P can be further metabolized by both the glycolytic pathway and the PPP. ${ }^{[84]}$ The PPP generates ribose 5-phosphate (R5P), a critical sub-strate for nucleotide synthesis. The PPP plays a critical role in regulating cancer cell growth by supplying cells with not only R5P but also NADPH for detoxification of intra-cellular ROS, reductive biosynthesis and ribose biogenesis.
Fructose-6-phosphate is isomerized to G6P in cells, and this accumulated G6P is diverted into the PPP, an alternative metabolic pathway that can provide substrates for the later steps in glycolysis. Glucose-6-phosphate dehydrogenase (G6PD) is mediated by various signals, and it acts as a sensor of cellular $\mathrm{NADP}^{+}$levels. Increased $\mathrm{NADP}^{+}$activates G6PD by competing with NADPH for binding to this enzyme (G6PD), and determines the amount of NADPH by controlling the metabolism of glucose via the PPP. ${ }^{[85]}$ The increased flow through the PPP lowers apoptosis because of an increased generation of reduced GSH and removal of ROS in cells. ${ }^{[25]}$ Elevated levels of G6PD in association with higher levels of PPP-derived metabolites suggest a prominent role of this pathway in metabolic alterations of human cancer. ${ }^{[86,87]} \mathrm{G} 6 \mathrm{PD}$ inhibition decreases cancer cell survival, NADPH levels and increases production of ROS, suggesting that the PPP plays an important role in the regulation of redox homeostasis. ${ }^{[88,89]}$ G6PD is associated with adriamycin resistance in breast cancer cells using proteomics analysis. ${ }^{[90]}$

The PPP is positively regulated by $\mathrm{K}-\mathrm{ras}^{\mathrm{G} 12 \mathrm{D}}$, PI3K, ${ }^{[91]}$ mTORC1, ${ }^{[92]}$ Tap73, ${ }^{[93,94]}$ HSP27, ${ }^{[95]}$ SREBP, ${ }^{[92]}$ the ataxia-telangiectasia mutated kinase, protein kinase A, NADP and glycolytic inhibition (TIGAR, ${ }^{[25]}$ PKM2 and PGAM). The PPP is negatively regulated by $\mathrm{p} 53$, PTEN, ${ }^{[96]}$ AMPK, ${ }^{[3]}$ cyclic adenosine monophosphate, cyclic AMP-response element modulator and aldosterone. ${ }^{[97]}$ TAp73, the transcriptionally competent isoform of the p53 family protein p73, was identified as a transcriptional regulator of G6PD. ${ }^{[94]}$

The PPP is a well-established metabolic pathway, but the mechanism that activates the PPP has yet to be identified. TIGAR, a target of p53, inhibits glycolysis and diverts the carbon flux into the PPP, resulting in the passive promotion of PPP activity. NADPH production pathway is targeted by nuclear factor E2 p45-related factor 2 (Nrf2). ${ }^{[98]} \mathrm{Nrf} 2$, a bZIP transcription factor, plays a central role in the regulation (basal and/or inducible expression) of phase 2 genes by binding to the anti-oxidant response element in their promoters. A previous study focused on the cytoprotective aspect of the PPP by analyzing NADPH production as reducing equivalents for ROS elimination. ${ }^{[99]}$ The PPP genes are strongly activated by $\mathrm{Nrf} 2$ in proliferating cells in which the PI3K-Akt pathway is active, and increased expression of the PPP genes contributes to cell proliferation. ${ }^{\text {[98] }}$

Under basal conditions, Keap1 binds to the ETGE and DLG motifs in Nrf2 and recruits Nrf2 to the Keap1-Cul3-E3 ubiquitin ligase complex, leading to ubiquitination and subsequent degradation of Nrf2. Oxidative stress or electrophiles can cause a conformational change in the Keap1-Cul3-E3 ubiquitin ligase by acting on specific cysteine residues in Keap1. ${ }^{[100]}$ These changes disrupt Nrf2-Keap1 binding at 
the DLG domain, resulting in stabilization of $\mathrm{Nrf2}$ and translocation of free Nrf2 to the nucleus. ${ }^{[101]} \mathrm{Nrf} 2$ is aberrantly accumulated in many types of cancer, and its expression is associated with a poor prognosis in patients. ${ }^{[102-106]}$ In addition, Nrf2 expression is induced during the course of drug resistance in gastric cancer, ${ }^{[107]}$ $\mathrm{CRC}^{[108]}$ and esophageal SCC. ${ }^{[109]}$

\section{ROS and Energy Metabolism in Cancer Cells}

Oxygen free radicals are highly reactive with biological molecules, including DNA, proteins and lipids. The free radical reaction could cause oxidative modification of these biomolecules and alter their functions. Mitochondria generate ROS that are thought to augment intra-cellular oxidative stress. In all cells, the majority of ROS are by-products of mitochondrial respiration. Approximately, $2 \%$ of the molecular oxygen consumed during respiration is converted into the superoxide anion radical, the precursor of most ROS. Mitochondria possess at least nine known sites that are capable of generating superoxide anion, a progenitor ROS. ${ }^{[110]}$ A mild increase in the level of ROS may result in transient cellular alterations, whereas a severe increase of ROS in cells could cause irreversible oxidative damage, leading to cell death. ${ }^{[111]}$ In normal cells, the ROS level is tightly controlled by the endogenous anti-oxidant system. However, energy metabolism and ROS homeostasis in cancer cells are different from those in normal cells. During the transition phases from normal tissue to invasive carcinoma, ROS levels increase because of metabolic aberrations. ${ }^{[112]}$

Severe accumulation of cellular ROS under various endogenous and exogenous stress stimuli may induce fatal damage in cells that have inadequate stress responses or adaptation. In cancer cells, ROS stress may induce adaptive stress responses, including activation of redox-sensitive transcription factors, such as nuclear factor $\mathrm{\kappa B}$ and $\mathrm{Nrf} 2$. These responses lead to an increase in the expression of ROS-scavenging enzymes, such as SOD and glutathione (GSH), elevation of survival factors such as Bcl-2 and MCL1, and inhibition of cell death factors, such as caspases. ${ }^{[111,113,114]}$ ROS-mediated DNA mutations or deletions promote genomic instability and thus induce an additional mechanism for stress adaptation. All these events contribute to the survival of cells with high levels of ROS and maintain cellular viability. ${ }^{[15]}$ As these transcription factors also have roles in regulating the expression of genes that are responsible for proliferation, senescence evasion, angiogenesis and metastasis, and thus the redox adaptation processes may promote cancer development. ${ }^{[116,117]}$ The increase in GSH during the redox adaptation can enhance the export of certain anti-cancer drugs and their inactivation. This altered drug metabolism, together with enhanced cell survival, may render cancer cells more resistant to chemotherapeutic agents. ${ }^{[113,118,119]}$ Activation of oncogenes, aberrant metabolism, mitochondrial dysfunction and loss of functional p53 are intrinsic factors known to cause increased ROS production in cancer cells. ${ }^{[11]}$ In chemotherapy, 5-Fluorouracil (FU) generates mitochondrial ROS via a p53-dependent pathway. ${ }^{[120]}$ Tumor cells which adapt to oxidative stress by increasing the production of SOD2, Prx1 and Bcl-2 are resistant to 5-FU. ${ }^{[121]}$ Products of oxidative stress can slow cell-cycle progression of cancer cells, cause cell-cycle checkpoint arrest and interfere with the ability of anti-cancer drugs to kill cancer cells. ${ }^{[122]}$ The capacity of some chemotherapeutic agents to cause an imbalance in ROS levels offers a therapeutic opportunity for treating cancer.

Considering that cancer cells have increased ROS levels, they may be selectively sensitive to the damaging effects of further increasing ROS. Cancer cells frequently have increased expression of anti-oxidants to maintain homeostasis. Inhibiting anti-oxidants to expose cancer cells to endogenously produced ROS may be a therapeutic approach. ${ }^{[123]}$ In support of this model, several small molecule screens have identified compounds that specifically inhibit the growth of transformed cells. Piperlongumine increases ROS and apoptotic cell death in both cancer cells and normal cells engineered to have a cancer genotype, irrespective of p53 status, with little effect on dividing primary normal cells. ${ }^{[124]}$ Beta-phenylethyl isothiocyanate (PEITC) is a natural compound found in consumable cruciferous vegetables with chemopreventive activity. PEITC increases ROS and selectively kills cancer cells. ${ }^{[125]}$ Malignant cells are often resistant to conventional anti-cancer drugs. These cells are under intrinsic ROS stress, so using small molecules that induce ROS to kill such malignant cells may exert a therapeutic effect.

\section{Cancer Treatment}

Novel small molecules targeting metabolic regulators and glycolytic enzymes have been reported to exert anti-proliferative effects. ${ }^{[126]}$ Phloretin, a natural product with GLUT inhibitory activity found in apples and pears, exerts anti-tumor effects in HCC and color cancer cell lines. ${ }^{[127,128]}$ The WZB117 small molecule inhibitor of GLUT 1 was effective in inhibiting cancer cell growth both in vitro and in vivo. ${ }^{[129]}$ The widely used 3-bromopyruvate $(3-\mathrm{BrPA})^{[130]}$ depletes cellular ATP. A previous study showed that 3-BrPA inhibits HK2 expression and exhibits anti-proliferative effects when combined with daunorubicin in CRC cell lines ${ }^{[131]}$ and when combined with protein disulfide isomerase in HCC cell lines. ${ }^{[132]}$ DCA, a PDK-1 inhibitor, has reduced lactate production and increased responsiveness to 5-FU in MKN45 cells ${ }^{[76]}$ and CRC cell lines. ${ }^{[133]}$ DCA treatment exerts anti-proliferative effects and sorafenib resistance in HCC cell lines in vivo. ${ }^{[134]}$ Oxmate, a LDH inhibitor, combined with phenformin, has exhibited cytotoxic effects in diverse cancer cell lines, including colon cancer. ${ }^{[135]}$ Future studies should examine whether 
inhibitors of glycolytic enzymes and metabolite transporters are effective in preclinical or clinical settings and evaluate adverse effects and feasibility for clinical practice.

The Nrf2 transcription factor is an important modifier of cellular responses to oxidative stress. Stable RNAi-mediated knockdown of Nrf2 in human colon cancer cells suppressed tumor growth in a xenograft model with a reduction in blood vessel formation and VEGF expression. The Nrf2-inhibited cancer cells failed to accumulate HIF-1A protein under hypoxic conditions. ${ }^{[136]}$ HIF plays a crucial role in cellular adaptation to hypoxia and regulates the expression of genes responsible for glucose metabolism, angiogenesis and cell survival. Conventional anti-cancer therapies typically target actively dividing cells near the vasculature, though they function poorly in hypoxic regions. ${ }^{[137]}$ Cells in hypoxic regions are relatively quiescent, and these cells also tend to be refractory to agents targeting rapidly proliferating cells. $^{[138-140]}$

Novel therapeutic agents targeting the resistant hypoxic zones may provide additional anti-tumor activity and clinical benefit when combined with conventional treatments. Tirapazamine is a bioreductively activated, hypoxia-selective anti-tumor agent of the benzotriazine series; it is 35-450 times more cytotoxic to hypoxic cells than to well-oxygenated cells. ${ }^{[141]}$ Standard cisplatin chemoradiotherapy plus tirapazamine has not been superior to cisplatin chemoradiotherapy in either progression-free survival or overall survival in locally advanced cervix cancer. ${ }^{[142]} \mathrm{TH}-302$ is a novel therapeutic agent and a hypoxia-activated, cytotoxic prodrug with a 2-nitroimidazole component designed to release the DNA cross-linker bromo-isophosphoramide mustard when reduced by intra-cellular reductases in the setting of severe hypoxia. ${ }^{[143]}$ The phase II study by Borad et al. ${ }^{[144]}$ evaluated treatment of TH-302 in patients with either locally advanced or metastatic pancreatic cancer and found that the addition of TH-302 to gemcitabine resulted in a near doubling of progression-free survival and objective response with acceptable toxicity.

Many anti-cancer treatments regulating ROS levels have been demonstrated. NOV-002 is a GSH disulfide mimetic that alters the intra-cellular GSH/GSSG ratio by increasing GSSG levels via the induction of S-glutathionylation. ${ }^{[145]}$ NOV-002 modulates signaling pathways involved in tumor cell proliferation and metastasis and enhances anti-tumor immune responsiveness. NOV-002, in combination with neoadjuvant AC in patients with HER-2 negative breast cancer, was well tolerated and resulted in a favorable pCR rate in a phase II study. ${ }^{[146]}$ Sulfasalazine inhibits $\mathrm{xCT}$ (a cystine/glutamate transporter) and reduces the intra-cellular transport of cysteine required for GSH synthesis. ${ }^{[147]}$ Sulfasalazine in combination with conventional anti-cancer agents may be an effective therapy for refractory pancreatic cancer ${ }^{[148]}$ and small cell lung cancer. ${ }^{[149]}$ The small molecule 968 is identified to block glutaminase activation and inhibit the growth of cancer cells, and this enzyme shows potential as a therapeutic strategy against cancer. ${ }^{[150]}$

\section{Conclusions and Perspective}

This review describes recent investigations in mitochondrial metabolism, anaerobic glycolysis and the PPP in cancer. We also discussed the control of ROS levels by the endogenous anti-oxidant system. Key regulators related to cell death in the mitochondria are frequently altered in cancer cells, and mitochondria in cancer differ functionally and structurally from those of normal cells. Mitochondria dysfunction in cancer is associated with the activation of oncogenes and inactivation of tumor suppressors. Recent genetic and metabolic analyses have revealed the molecular mechanisms of genes that are involved in cancer metabolism and tumorigenesis. The alterations of gene expression in glycolysis are associated with poor prognosis and may be associated with chemoradiotherapy resistance. The PPP is positively regulated by oncogenes and regulates cancer cell growth by supplying cells with R5P and NADPH. Direct regulators that activate the PPP have been identified. ROS levels are increased during carcinogenesis from metabolic aberrations. Cancer cells frequently have increased expression of anti-oxidants to maintain homeostasis. Anti-cancer agents targeting ROS status may exert therapeutic effects. Novel small molecules targeting metabolite transporters, glycolytic enzymes and ROS status have been reported. However, further studies should examine whether these inhibitors are useful in cancer therapy and evaluate adverse effects and feasibility for use in clinical practice.

\section{Financial support and sponsorship}

Nil.

\section{Conflicts of interest}

There are no conflicts of interest.

\section{References}

1. Warburg O. On the origin of cancer cells. Science $1956 ; 123: 309-14$

2. Warburg O. On respiratory impairment in cancer cells. Science 1956;124:269-70.

3. Jones RG, Plas DR, Kubek S, Buzzai M, Mu J, Xu Y, Birnbaum MJ, Thompson CB. AMP-activated protein kinase induces a p53-dependent metabolic checkpoint. Mol Cell 2005;18:283-93.

4. Elstrom RL, Bauer DE, Buzzai M, Karnauskas R, Harris MH, Plas DR, Zhuang H, Cinalli RM, Alavi A, Rudin CM, Thompson CB. Akt stimulates aerobic glycolysis in cancer cells. Cancer Res 2004;64:3892-9.

5. Vousden KH, Ryan KM. p53 and metabolism. Nat Rev Cancer 2009;9:691-700.

6. Stambolic V, MacPherson D, Sas D, Lin Y, Snow B, Jang Y, Benchimol S, Mak TW. Regulation of PTEN transcription by p53. Mol Cell 2001;8:317-25. 
7. Ward GR, Wainwright PE. Prenatal ethanol and stress in mice: 1. pup behavioral development and maternal physiology. Physiol Behav 1989;45:533-40.

8. Galluzzi L, Kroemer G. Necroptosis: a specialized pathway of programmed necrosis. Cell 2008;135:1161-3.

9. Gogvadze V, Orrenius S, Zhivotovsky B. Mitochondria in cancer cells: what is so special about them? Trends Cell Biol 2008;18:165-73.

10. Fukuda R, Zhang H, Kim JW, Shimoda L, Dang CV, Semenza GL. HIF-1 regulates cytochrome oxidase subunits to optimize efficiency of respiration in hypoxic cells. Cell 2007;129:111-22.

11. Reed DJ. Glutathione: toxicological implications. Annu Rev Pharmacol Toxicol 1990;30:603-31.

12. Rabilloud T, Heller M, Rigobello MP, Bindoli A, Aebersold R, Lunardi J. The mitochondrial antioxidant defence system and its response to oxidative stress. Proteomics 2001;1:1105-10.

13. Banmeyer I, Marchand C, Clippe A, Knoops B. Human mitochondrial peroxiredoxin 5 protects from mitochondrial DNA damages induced by hydrogen peroxide. FEBS Lett 2005;579:2327-33.

14. Huh JY, Kim Y, Jeong J, Park J, Kim I, Huh KH, Kim YS, Woo HA, Rhee SG, Lee KJ, Ha H. Peroxiredoxin 3 is a key molecule regulating adipocyte oxidative stress, mitochondrial biogenesis, and adipokine expression. Antioxid Redox Signal 2012;16:229-43.

15. Nonn L, Williams RR, Erickson RP, Powis G. The absence of mitochondrial thioredoxin 2 causes massive apoptosis, exencephaly, and early embryonic lethality in homozygous mice. Mol Cell Biol 2003;23:916-22.

16. Lebovitz RM, Zhang H, Vogel H, Cartwright J Jr, Dionne L, Lu N, Huang S, Matzuk MM. Neurodegeneration, myocardial injury, and perinatal death in mitochondrial superoxide dismutase-deficient mice. Proc Natl Acad Sci U S A 1996; 93:9782-7.

17. Hinerfeld D, Traini MD, Weinberger RP, Cochran B, Doctrow SR, Harry J, Melov S. Endogenous mitochondrial oxidative stress: neurodegeneration, proteomic analysis, specific respiratory chain defects, and efficacious antioxidant therapy in superoxide dismutase 2 null mice. $J$ Neurochem 2004;88:657-67.

18. Canter JA, Kallianpur AR, Parl FF, Millikan RC. Mitochondrial DNA G10398A polymorphism and invasive breast cancer in African-American women. Cancer Res 2005;65:8028-33.

19. Darvishi K, Sharma S, Bhat AK, Rai E, Bamezai RN. Mitochondrial DNA G10398A polymorphism imparts maternal Haplogroup $\mathrm{N}$ a risk for breast and esophageal cancer. Cancer Lett 2007;249:249-55.

20. Liu VW, Wang Y, Yang HJ, Tsang PC, Ng TY, Wong LC, Nagley P, Ngan HY. Mitochondrial DNA variant $16189 \mathrm{~T}>\mathrm{C}$ is associated with susceptibility to endometrial cancer. Hum Mutat 2003;22:173-4.

21. Ishikawa $K$, Takenaga $K$, Akimoto $M$, Koshikawa N, Yamaguchi A, Imanishi H, Nakada K, Honma Y, Hayashi J. ROS-generating mitochondrial DNA mutations can regulate tumor cell metastasis. Science 2008;320:661-4.

22. Brandon M, Baldi P, Wallace DC. Mitochondrial mutations in cancer. Oncogene 2006;25:4647-62.

23. Matoba S, Kang JG, Patino WD, Wragg A, Boehm M, Gavrilova O, Hurley PJ, Bunz F, Hwang PM. p53 regulates mitochondrial respiration. Science 2006;312:1650-3.

24. Buchwald P, Krummeck G, Rodel G. Immunological identification of yeast SCO1 protein as a component of the inner mitochondrial membrane. Mol Gen Genet 1991;229:413-20.
25. Bensaad K, Tsuruta A, Selak MA, Vidal MN, Nakano K, Bartrons R, Gottlieb E, Vousden KH. TIGAR, a p53-inducible regulator of glycolysis and apoptosis. Cell 2006;126:107-20.

26. Zhou X, Xie W, Li Q, Zhang Y, Zhang J, Zhao X, Liu J, Huang G. TIGAR is correlated with maximal standardized uptake value on FDG-PET and survival in non-small cell lung cancer. PLoS One 2013;8:e80576.

27. Kim JW, Tchernyshyov I, Semenza GL, Dang CV. HIF-1-mediated expression of pyruvate dehydrogenase kinase: a metabolic switch required for cellular adaptation to hypoxia. Cell Metab 2006;3:177-85.

28. Papandreou I, Cairns RA, Fontana L, Lim AL, Denko NC. HIF-1 mediates adaptation to hypoxia by actively downregulating mitochondrial oxygen consumption. Cell Metab 2006;3:187-97.

29. Abel F, Sjoberg RM, Nilsson S, Kogner P, Martinsson T. Imbalance of the mitochondrial pro- and anti-apoptotic mediators in neuroblastoma tumours with unfavourable biology. Eur J Cancer 2005;41:635-46.

30. Shimizu S, Shinohara Y, Tsujimoto Y. Bax and Bcl-xL independently regulate apoptotic changes of yeast mitochondria that require VDAC but not adenine nucleotide translocator. Oncogene 2000;19:4309-18.

31. Mathupala SP, Ko YH, Pedersen PL. Hexokinase II: cancer's double-edged sword acting as both facilitator and gatekeeper of malignancy when bound to mitochondria. Oncogene 2006;25:4777-86.

32. Pastorino JG, Shulga N, Hoek JB. Mitochondrial binding of hexokinase II inhibits Bax-induced cytochrome c release and apoptosis. J Biol Chem 2002;277:7610-8.

33. Kennedy SG, Kandel ES, Cross TK, Hay N. Akt/protein kinase $\mathrm{B}$ inhibits cell death by preventing the release of cytochrome $\mathrm{c}$ from mitochondria. Mol Cell Biol 1999;19:5800-10.

34. Bijur GN, Jope RS. Rapid accumulation of Akt in mitochondria following phosphatidylinositol 3-kinase activation. J Neurochem 2003;87:1427-35.

35. Nakano K, Vousden KH. PUMA, a novel proapoptotic gene, is induced by p53. Mol Cell 2001;7:683-94.

36. Oda E, Ohki R, Murasawa H, Nemoto J, Shibue T, Yamashita T, Tokino T, Taniguchi T, Tanaka N. Noxa, a BH3-only member of the Bcl-2 family and candidate mediator of p53-induced apoptosis. Science 2000;288:1053-8.

37. Zhong H, De Marzo AM, Laughner E, Lim M, Hilton DA, Zagzag D, Buechler P, Isaacs WB, Semenza GL, Simons JW. Overexpression of hypoxia-inducible factor 1alpha in common human cancers and their metastases. Cancer Res 1999;59:5830-5.

38. Zhang ZG, Zhang QN, Wang XH, Tian JH. Hypoxia-inducible factor 1 alpha (HIF-1alpha) as a prognostic indicator in patients with gastric tumors: a meta-analysis. Asian Pac J Cancer Prev 2013;14:4195-8.

39. Matsuyama T, Nakanishi K, Hayashi T, Yoshizumi Y, Aiko S, Sugiura Y, Tanimoto T, Uenoyama M, Ozeki Y, Maehara T. Expression of hypoxia-inducible factor-1alpha in esophageal squamous cell carcinoma. Cancer Sci 2005;96:176-82.

40. Ogane N, Yasuda M, Shimizu M, Miyazawa M, Kamoshida S, Ueda A, Takata K, Sakuma Y, Miyagi Y, Kameda Y. Clinicopathological implications of expressions of hypoxia-related molecules in esophageal superficial squamous cell carcinoma. Ann Diagn Pathol 2010;14:23-9.

41. Lin S, Ma R, Zheng XY, Yu H, Liang X, Lin H, Cai XJ. Meta-analysis of immunohistochemical expression of hypoxia inducible factor-1alpha as a prognostic role in gastric cancer. World J Gastroenterol 2014;20:1107-13.

42. Baba $\mathrm{Y}$, Nosho $\mathrm{K}$, Shima $\mathrm{K}$, Irahara $\mathrm{N}$, Chan $\mathrm{AT}$, 
Meyerhardt JA, Chung DC, Giovannucci EL, Fuchs CS, Ogino S. HIF1A overexpression is associated with poor prognosis in a cohort of 731 colorectal cancers. Am J Pathol 2010;176:2292-301.

43. Zheng SS, Chen XH, Yin X, Zhang BH. Prognostic significance of HIF-1alpha expression in hepatocellular carcinoma: a meta-analysis. PLoS One 2013;8:e65753.

44. Nakamura J, Kitajima Y, Kai K, Mitsuno M, Ide T, Hashiguchi K, Hiraki M, Miyazaki K. Hypoxia-inducible factor-1alpha expression predicts the response to 5-fluorouracil-based adjuvant chemotherapy in advanced gastric cancer. Oncol Rep 2009;22:693-9.

45. Nakamura J, Kitajima Y, Kai K, Hashiguchi K, Hiraki M, Noshiro H, Miyazaki K. HIF-1alpha is an unfavorable determinant of relapse in gastric cancer patients who underwent curative surgery followed by adjuvant 5-FU chemotherapy. Int $J$ Cancer 2010;127:1158-71.

46. Griffiths EA, Pritchard SA, McGrath SM, Valentine HR, Price PM, Welch IM, West CM. Hypoxia-associated markers in gastric carcinogenesis and HIF-2alpha in gastric and gastro-oesophageal cancer prognosis. $\mathrm{Br} J$ Cancer 2008;98:965-73.

47. Rasheed S, Harris AL, Tekkis PP, Turley H, Silver A, McDonald PJ, Talbot IC, Glynne-Jones R, Northover JM, Guenther T. Hypoxia-inducible factor-1alpha and -2alpha are expressed in most rectal cancers but only hypoxia-inducible factor-1alpha is associated with prognosis. $\mathrm{Br} J$ Cancer 2009; 100:1666-73.

48. Fernandez PC, Frank SR, Wang L, Schroeder M, Liu S, Greene J, Cocito A, Amati B. Genomic targets of the human c-Myc protein. Genes Dev 2003;17:1115-29.

49. Lutz W, Leon J, Eilers M. Contributions of Myc to tumorigenesis. Biochim Biophys Acta 2002;1602:61-71.

50. de Souza CR, Leal MF, Calcagno DQ, Costa Sozinho EK, Borges Bdo N, Montenegro RC, Dos Santos AK, Dos Santos SE, Ribeiro HF, Assumpcao PP, de Arruda Cardoso Smith M, Burbano RR. MYC deregulation in gastric cancer and its clinicopathological implications. PLoS One 2013;8:e64420.

51. Joost HG, Thorens B. The extended GLUT-family of sugar/polyol transport facilitators: nomenclature, sequence characteristics, and potential function of its novel members (review). Mol Membr Biol 2001;18:247-56.

52. Younes M, Lechago LV, Somoano JR, Mosharaf M, Lechago J. Immunohistochemical detection of Glut3 in human tumors and normal tissues. Anticancer Res 1997; 17:2747-50.

53. Ayala FR, Rocha RM, Carvalho KC, Carvalho AL, da Cunha IW, Lourenco SV, Soares FA. GLUT1 and GLUT3 as potential prognostic markers for Oral Squamous Cell Carcinoma. Molecules 2010;15:2374-87.

54. Fonteyne P, Casneuf V, Pauwels P, Van Damme N, Peeters M, Dierckx R, Van de Wiele C. Expression of hexokinases and glucose transporters in treated and untreated oesophageal adenocarcinoma. Histol Histopathol 2009;24:971-7.

55. Sawayama H, Ishimoto T, Watanabe M, Yoshida N, Baba Y, Sugihara H, Izumi D, Kurashige J, Baba H. High expression of glucose transporter 1 on primary lesions of esophageal squamous cell carcinoma is associated with hematogenous recurrence. Ann Surg Oncol 2014;21:1756-62.

56. Kawamura T, Kusakabe T, Sugino T, Watanabe K, Fukuda T, Nashimoto A, Honma K, Suzuki T. Expression of glucose transporter-1 in human gastric carcinoma: association with tumor aggressiveness, metastasis, and patient survival. Cancer 2001;92:634-41.

57. Haber RS, Rathan A, Weiser KR, Pritsker A, Itzkowitz SH,
Bodian C, Slater G, Weiss A, Burstein DE. GLUT1 glucose transporter expression in colorectal carcinoma: a marker for poor prognosis. Cancer 1998;83:34-40.

58. Mueckler M, Caruso C, Baldwin SA, Panico M, Blench I, Morris HR, Allard WJ, Lienhard GE, Lodish HF. Sequence and structure of a human glucose transporter. Science 1985;229:941-5.

59. Deng D, Xu C, Sun P, Wu J, Yan C, Hu M, Yan N. Crystal structure of the human glucose transporter GLUT1. Nature 2014;510:121-5.

60. Griffiths EA, Pritchard SA, Welch IM, Price PM, West CM. Is the hypoxia-inducible factor pathway important in gastric cancer? Eur J Cancer 2005;41:2792-805.

61. Dang CV, Le A, Gao P. MYC-induced cancer cell energy metabolism and therapeutic opportunities. Clin Cancer Res 2009;15:6479-83.

62. Yun J, Rago C, Cheong I, Pagliarini R, Angenendt P, Rajagopalan H, Schmidt K, Willson JK, Markowitz S, Zhou S, Diaz LA Jr, Velculescu VE, Lengauer C, Kinzler KW, Vogelstein B, Papadopoulos N. Glucose deprivation contributes to the development of KRAS pathway mutations in tumor cells. Science 2009;325:1555-9.

63. Kawada K, Nakamoto Y, Kawada M, Hida K, Matsumoto T, Murakami T, Hasegawa S, Togashi K, Sakai Y. Relationship between 18F-fluorodeoxyglucose accumulation and KRAS/BRAF mutations in colorectal cancer. Clin Cancer Res 2012;18:1696-703.

64. Yang W, Zheng Y, Xia Y, Ji H, Chen X, Guo F, Lyssiotis CA, Aldape K, Cantley LC, Lu Z. ERK1/2-dependent phosphorylation and nuclear translocation of PKM2 promotes the Warburg effect. Nat Cell Biol 2012;14:1295-304.

65. Young CD, Lewis AS, Rudolph MC, Ruehle MD, Jackman MR, Yun UJ, Ilkun O, Pereira R, Abel ED, Anderson SM. Modulation of glucose transporter 1 (GLUT1) expression levels alters mouse mammary tumor cell growth in vitro and in vivo. PLoS One 2011;6:e23205.

66. Kwee SA, Hernandez B, Chan O, Wong L. Choline kinase alpha and hexokinase-2 protein expression in hepatocellular carcinoma: association with survival. PLoS One 2012;7:e46591.

67. Paudyal B, Paudyal P, Oriuchi N, Tsushima Y, Nakajima T, Endo K. Clinical implication of glucose transport and metabolism evaluated by $18 \mathrm{~F}-\mathrm{FDG}$ PET in hepatocellular carcinoma. Int J Oncol 2008;33:1047-54.

68. Gong L, Cui Z, Chen P, Han H, Peng J, Leng X. Reduced survival of patients with hepatocellular carcinoma expressing hexokinase II. Med Oncol 2012;29:909-14.

69. Mathupala SP, Ko YH, Pedersen PL. Hexokinase-2 bound to mitochondria: cancer's stygian link to the "Warburg Effect" and a pivotal target for effective therapy. Semin Cancer Biol 2009;19:17-24.

70. David CJ, Chen M, Assanah M, Canoll P, Manley JL. HnRNP proteins controlled by $\mathrm{c}-\mathrm{Myc}$ deregulate pyruvate kinase mRNA splicing in cancer. Nature 2010;463:364-8.

71. Clower CV, Chatterjee D, Wang Z, Cantley LC, Vander Heiden MG, Krainer AR. The alternative splicing repressors hnRNP A1/A2 and PTB influence pyruvate kinase isoform expression and cell metabolism. Proc Natl Acad Sci U S A 2010;107:1894-9.

72. Christofk HR, Vander Heiden MG, Harris MH, Ramanathan A, Gerszten RE, Wei R, Fleming MD, Schreiber SL, Cantley LC. The M2 splice isoform of pyruvate kinase is important for cancer metabolism and tumour growth. Nature 2008;452:230-3.

73. Yang W, Lu Z. Regulation and function of pyruvate kinase M2 in cancer. Cancer Lett 2013;339:153-8. 
74. Tamada M, Suematsu M, Saya H. Pyruvate kinase M2: multiple faces for conferring benefits on cancer cells. Clin Cancer Res 2012;18:5554-61.

75. Kaplon J, Zheng L, Meissl K, Chaneton B, Selivanov VA, Mackay G, van der Burg SH, Verdegaal EM, Cascante M, Shlomi T, Gottlieb E, Peeper DS. A key role for mitochondrial gatekeeper pyruvate dehydrogenase in oncogene-induced senescence. Nature 2013;498:109-12.

76. Hur H, Xuan Y, Kim YB, Lee G, Shim W, Yun J, Ham IH, Han SU. Expression of pyruvate dehydrogenase kinase-1 in gastric cancer as a potential therapeutic target. Int $J$ Oncol 2013;42:44-54.

77. Lu CW, Lin SC, Chien CW, Lin SC, Lee CT, Lin BW, Lee JC, Tsai SJ. Overexpression of pyruvate dehydrogenase kinase 3 increases drug resistance and early recurrence in colon cancer. Am J Pathol 2011;179:1405-14.

78. Fantin VR, St-Pierre J, Leder P. Attenuation of LDH-A expression uncovers a link between glycolysis, mitochondrial physiology, and tumor maintenance. Cancer Cell 2006;9:425-34.

79. Goldman RD, Kaplan NO, Hall TC. Lactic dehydrogenase in human neoplastic tissues. Cancer Res 1964;24:389-99.

80. Zhang Y, Zhang X, Wang X, Gan L, Yu G, Chen Y, Liu K, Li P, Pan J, Wang J, Qin S. Inhibition of LDH-A by lentivirus-mediated small interfering RNA suppresses intestinal-type gastric cancer tumorigenicity through the downregulation of Oct4. Cancer Lett 2012;321:45-54.

81. Koukourakis MI, Giatromanolaki A, Sivridis E, Gatter KC, Harris AL, Tumour Angiogenesis Research Group. Lactate dehydrogenase 5 expression in operable colorectal cancer: strong association with survival and activated vascular endothelial growth factor pathway-A report of the Tumour Angiogenesis Research Group. J Clin Oncol 2006;24:4301-8.

82. Fan J, Hitosugi T, Chung TW, Xie J, Ge Q, Gu TL, Polakiewicz RD, Chen GZ, Boggon TJ, Lonial S, Khuri FR, Kang S, Chen J. Tyrosine phosphorylation of lactate dehydrogenase A is important for $\mathrm{NADH} / \mathrm{NAD}(+)$ redox homeostasis in cancer cells. Mol Cell Biol 2011;31:4938-50.

83. Sheng SL, Liu JJ, Dai YH, Sun XG, Xiong XP, Huang G. Knockdown of lactate dehydrogenase A suppresses tumor growth and metastasis of human hepatocellular carcinoma. FEBS J 2012;279:3898-910.

84. Jiang $\mathrm{P}, \mathrm{Du} \mathrm{W}, \mathrm{Wu} \mathrm{M}$. Regulation of the pentose phosphate pathway in cancer. Protein Cell 2014;5:592-602.

85. Kletzien RF, Harris PK, Foellmi LA. Glucose-6-phosphate dehydrogenase: a "housekeeping" enzyme subject to tissue-specific regulation by hormones, nutrients, and oxidant stress. FASEB J 1994;8:174-81.

86. Tsouko E, Khan AS, White MA, Han JJ, Shi Y, Merchant FA, Sharpe MA, Xin L, Frigo DE. Regulation of the pentose phosphate pathway by an androgen receptor-mTOR-mediated mechanism and its role in prostate cancer cell growth. Oncogenesis 2014;3:e103.

87. Wang J, Yuan W, Chen Z, Wu S, Chen J, Ge J, Hou F, Chen Z. Overexpression of G6PD is associated with poor clinical outcome in gastric cancer. Tumour Biol 2012;33:95-101.

88. Lucarelli G, Galleggiante V, Rutigliano M, Sanguedolce F, Cagiano S, Bufo P, Lastilla G, Maiorano E, Ribatti D, Giglio A, Serino G, Vavallo A, Bettocchi C, Selvaggi FP, Battaglia M, Ditonno P. Metabolomic profile of glycolysis and the pentose phosphate pathway identifies the central role of glucose-6-phosphate dehydrogenase in clear cell-renal cell carcinoma. Oncotarget 2015;6:13371-86

89. Zhang C, Zhang Z, Zhu Y, Qin S. Glucose-6-phosphate dehydrogenase: a biomarker and potential therapeutic target for cancer. Anticancer Agents Med Chem 2014;14:280-9.

90. Wang Z, Liang S, Lian X, Liu L, Zhao S, Xuan Q, Guo L, Liu H, Yang Y, Dong T, Liu Y, Liu Z, Zhang Q. Identification of proteins responsible for adriamycin resistance in breast cancer cells using proteomics analysis. Sci Rep 2015;5:9301.

91. Ying H, Kimmelman AC, Lyssiotis CA, Hua S, Chu GC, Fletcher-Sananikone E, Locasale JW, Son J, Zhang H, Coloff JL, Yan H, Wang W, Chen S, Viale A, Zheng H, Paik JH, Lim C, Guimaraes AR, Martin ES, Chang J, Hezel AF, Perry SR, Hu J, Gan B, Xiao Y, Asara JM, Weissleder R, Wang YA, Chin L, Cantley LC, DePinho RA. Oncogenic Kras maintains pancreatic tumors through regulation of anabolic glucose metabolism. Cell 2012;149:656-70.

92. Duvel K, Yecies JL, Menon S, Raman P, Lipovsky AI, Souza AL, Triantafellow E, Ma Q, Gorski R, Cleaver S, Vander Heiden MG, MacKeigan JP, Finan PM, Clish CB, Murphy LO, Manning BD. Activation of a metabolic gene regulatory network downstream of mTOR complex 1. Mol Cell 2010;39:171-83.

93. Jiang P, Du W, Yang X. A critical role of glucose-6-phosphate dehydrogenase in TAp73-mediated cell proliferation. Cell Cycle 2013;12:3720-6.

94. Du W, Jiang P, Mancuso A, Stonestrom A, Brewer MD, Minn AJ, Mak TW, Wu M, Yang X. TAp73 enhances the pentose phosphate pathway and supports cell proliferation. Nat Cell Biol 2013;15:991-1000.

95. Cosentino C, Grieco D, Costanzo V. ATM activates the pentose phosphate pathway promoting anti-oxidant defence and DNA repair. EMBO J 2011;30:546-55.

96. Hong X, Song R, Song H, Zheng T, Wang J, Liang Y, Qi S, Lu Z, Song X, Jiang H, Liu L, Zhang Z. PTEN antagonises Tcl1/hnRNPK-mediated G6PD pre-mRNA splicing which contributes to hepatocarcinogenesis. Gut 2014;63:1635-47.

97. Leopold JA, Dam A, Maron BA, Scribner AW, Liao R, Handy DE, Stanton RC, Pitt B, Loscalzo J. Aldosterone impairs vascular reactivity by decreasing glucose-6-phosphate dehydrogenase activity. Nat Med 2007;13:189-97.

98. Mitsuishi Y, Taguchi K, Kawatani Y, Shibata T, Nukiwa T, Aburatani H, Yamamoto M, Motohashi H. Nrf2 redirects glucose and glutamine into anabolic pathways in metabolic reprogramming. Cancer Cell 2012;22:66-79.

99. Wu KC, Cui JY, Klaassen CD. Beneficial role of Nrf2 in regulating NADPH generation and consumption. Toxicol Sci 2011;123:590-600.

100. Kobayashi A, Kang MI, Okawa H, Ohtsuji M, Zenke Y, Chiba T, Igarashi K, Yamamoto M. Oxidative stress sensor Keap1 functions as an adaptor for Cul3-based E3 ligase to regulate proteasomal degradation of Nrf2. Mol Cell Biol 2004;24:7130-9.

101. Jaramillo MC, Zhang DD. The emerging role of the Nrf2-Keap1 signaling pathway in cancer. Genes Dev 2013;27:2179-91.

102. Solis LM, Behrens C, Dong W, Suraokar M, Ozburn NC, Moran CA, Corvalan AH, Biswal S, Swisher SG, Bekele BN, Minna JD, Stewart DJ, Wistuba II. Nrf2 and Keap1 abnormalities in non-small cell lung carcinoma and association with clinicopathologic features. Clin Cancer Res 2010;16:3743-53.

103. Fer ND, Shoemaker RH, Monks A. Adaphostin toxicity in a sensitive non-small cell lung cancer model is mediated through Nrf2 signaling and heme oxygenase 1. J Exp Clin Cancer Res 2010;29:91

104. Martinez VD, Vucic EA, Thu KL, Pikor LA, Lam S, Lam WL. Disruption of KEAP1/CUL3/RBX1 E3-ubiquitin ligase complex components by multiple genetic mechanisms: 
association with poor prognosis in head and neck cancer. Head Neck 2015;37:727-34.

105. Onodera Y, Motohashi H, Takagi K, Miki Y, Shibahara Y, Watanabe M, Ishida T, Hirakawa H, Sasano H, Yamamoto M, Suzuki T. NRF2 immunolocalization in human breast cancer patients as a prognostic factor. Endocr Relat Cancer 2014;21:241-52.

106. Soini Y, Eskelinen M, Juvonen P, Karja V, Haapasaari KM, Saarela A, Karihtala P. Nuclear Nrf2 expression is related to a poor survival in pancreatic adenocarcinoma. Pathol Res Pract 2014;210:35-9.

107. Kawasaki Y, Ishigami S, Arigami T, Uenosono Y, Yanagita S, Uchikado Y, Kita Y, Nishizono Y, Okumura H, Nakajo A, Kijima Y, Maemura K, Natsugoe S. Clinicopathological significance of nuclear factor (erythroid-2)-related factor 2 (Nrf2) expression in gastric cancer. BMC Cancer 2015;15:5.

108. Yang Y, Cai X, Yang J, Sun X, Hu C, Yan Z, Xu X, Lu W, Wang $\mathrm{X}$, Cao P. Chemoprevention of dietary digitoflavone on colitis-associated colon tumorigenesis through inducing Nrf2 signaling pathway and inhibition of inflammation. Mol Cancer 2014;13:48.

109. Kawasaki Y, Okumura H, Uchikado Y, Kita Y, Sasaki K, Owaki T, Ishigami S, Natsugoe S. Nrf2 is useful for predicting the effect of chemoradiation therapy on esophageal squamous cell carcinoma. Ann Surg Oncol 2014;21:2347-52.

110. Andreyev AY, Kushnareva YE, Starkov AA. Mitochondrial metabolism of reactive oxygen species. Biochemistry (Mosc) 2005;70:200-14

111. Trachootham D, Alexandre J, Huang P. Targeting cancer cells by ROS-mediated mechanisms: a radical therapeutic approach? Nat Rev Drug Discov 2009;8:579-91.

112. Klaunig JE, Kamendulis LM. The role of oxidative stress in carcinogenesis. Annu Rev Pharmacol Toxicol 2004;44:239-67.

113. Sullivan R, Graham CH. Chemosensitization of cancer by nitric oxide. Curr Pharm Des 2008;14:1113-23.

114. Chen EI, Hewel J, Krueger JS, Tiraby C, Weber MR, Kralli A, Becker K, Yates JR 3rd, Felding-Habermann B. Adaptation of energy metabolism in breast cancer brain metastases. Cancer Res 2007;67:1472-86.

115. Young TW, Mei FC, Yang G, Thompson-Lanza JA, Liu J, Cheng X. Activation of antioxidant pathways in ras-mediated oncogenic transformation of human surface ovarian epithelial cells revealed by functional proteomics and mass spectrometry. Cancer Res 2004;64:4577-84.

116. Xia C, Meng Q, Liu LZ, Rojanasakul Y, Wang XR, Jiang BH. Reactive oxygen species regulate angiogenesis and tumor growth through vascular endothelial growth factor. Cancer Res 2007;67:10823-30.

117. Kondoh H, Lleonart ME, Bernard D, Gil J. Protection from oxidative stress by enhanced glycolysis; a possible mechanism of cellular immortalization. Histol Histopathol 2007;22:85-90.

118. Pervaiz S, Clement MV. Tumor intracellular redox status and drug resistance-Serendipity or a causal relationship? Curr Pharm Des 2004;10:1969-77.

119. Tiligada E. Chemotherapy: induction of stress responses. Endocr Relat Cancer 2006;13 Suppl 1:S115-24.

120. Hwang PM, Bunz F, Yu J, Rago C, Chan TA, Murphy MP, Kelso GF, Smith RA, Kinzler KW, Vogelstein B. Ferredoxin reductase affects p53-dependent, 5 -fluorouracil-induced apoptosis in colorectal cancer cells. Nat Med 2001;7:1111-7.

121. Hwang IT, Chung YM, Kim JJ, Chung JS, Kim BS, Kim HJ, Kim JS, Yoo YD. Drug resistance to 5-FU linked to reactive oxygen species modulator 1. Biochem Biophys Res Commun 2007;359:304-10
122. Conklin KA. Chemotherapy-associated oxidative stress: impact on chemotherapeutic effectiveness. Integr Cancer Ther 2004;3:294-300.

123. Sullivan LB, Chandel NS. Mitochondrial reactive oxygen species and cancer. Cancer Metab 2014;2:17.

124. Raj L, Ide T, Gurkar AU, Foley M, Schenone M, Li X, Tolliday NJ, Golub TR, Carr SA, Shamji AF, Stern AM, Mandinova A, Schreiber SL, Lee SW. Selective killing of cancer cells by a small molecule targeting the stress response to ROS. Nature 2011;475:231-4.

125. Trachootham D, Zhou Y, Zhang H, Demizu Y, Chen Z, Pelicano H, Chiao PJ, Achanta G, Arlinghaus RB, Liu J, Huang P. Selective killing of oncogenically transformed cells through a ROS-mediated mechanism by beta-phenylethyl isothiocyanate. Cancer Cell 2006;10:241-52.

126. Sawayama H, Ishimoto T, Watanabe M, Yoshida N, Sugihara H, Kurashige J, Hirashima K, Iwatsuki M, Baba Y, Oki E, Morita M, Shiose Y, Baba H. Small molecule agonists of PPAR-gamma exert therapeutic effects in esophageal cancer. Cancer Res 2014;74:575-85.

127. Cao X, Fang L, Gibbs S, Huang Y, Dai Z, Wen P, Zheng X, Sadee W, Sun D. Glucose uptake inhibitor sensitizes cancer cells to daunorubicin and overcomes drug resistance in hypoxia. Cancer Chemother Pharmacol 2007;59:495-505.

128. Wu CH, Ho YS, Tsai CY, Wang YJ, Tseng H, Wei PL, Lee CH, Liu RS, Lin SY. In vitro and in vivo study of phloretin-induced apoptosis in human liver cancer cells involving inhibition of type II glucose transporter. Int J Cancer 2009;124:2210-9.

129. Liu Y, Cao Y, Zhang W, Bergmeier S, Qian Y, Akbar H, Colvin $\mathrm{R}$, Ding $\mathrm{J}$, Tong $\mathrm{L}$, Wu $\mathrm{S}$, Hines $\mathrm{J}$, Chen $\mathrm{X}$. A small-molecule inhibitor of glucose transporter 1 downregulates glycolysis, induces cell-cycle arrest, and inhibits cancer cell growth in vitro and in vivo. Mol Cancer Ther 2012;11:1672-82.

130. Ganapathy-Kanniappan S, Vali M, Kunjithapatham R, Buijs M, Syed LH, Rao PP, Ota S, Kwak BK, Loffroy R, Geschwind JF. 3-bromopyruvate: a new targeted antiglycolytic agent and a promise for cancer therapy. Curr Pharm Biotechnol 2010;11:510-7.

131. Zhou Y, Tozzi F, Chen J, Fan F, Xia L, Wang J, Gao G, Zhang $\mathrm{A}$, Xia $\mathrm{X}$, Brasher $\mathrm{H}$, Widger $\mathrm{W}$, Ellis LM, Weihua Z. Intracellular ATP levels are a pivotal determinant of chemoresistance in colon cancer cells. Cancer Res 2012;72:304-14.

132. Yu SJ, Yoon JH, Yang JI, Cho EJ, Kwak MS, Jang ES, Lee JH, Kim YJ, Lee HS, Kim CY. Enhancement of hexokinase II inhibitor-induced apoptosis in hepatocellular carcinoma cells via augmenting ER stress and anti-angiogenesis by protein disulfide isomerase inhibition. J Bioenerg Biomembr 2012;44:101-15.

133. Tong J, Xie G, He J, Li J, Pan F, Liang H. Synergistic antitumor effect of dichloroacetate in combination with 5-fluorouracil in colorectal cancer. $J$ Biomed Biotechnol 2011;2011:740564

134. Shen YC, Ou DL, Hsu C, Lin KL, Chang CY, Lin CY, Liu SH, Cheng AL. Activating oxidative phosphorylation by a pyruvate dehydrogenase kinase inhibitor overcomes sorafenib resistance of hepatocellular carcinoma. Br J Cancer 2013;108:72-81.

135. Miskimins WK, Ahn HJ, Kim JY, Ryu S, Jung YS, Choi JY. Synergistic anti-cancer effect of phenformin and oxamate. PLoS One 2014;9:e85576.

136. Kim TH, Hur EG, Kang SJ, Kim JA, Thapa D, Lee YM, $\mathrm{Ku}$ SK, Jung Y, Kwak MK. NRF2 blockade suppresses colon tumor angiogenesis by inhibiting hypoxia-induced activation of HIF-1alpha. Cancer Res 2011;71:2260-75. 
137. Minchinton AI, Tannock IF. Drug penetration in solid tumours. Nat Rev Cancer 2006;6:583-92.

138. Hockel M, Vaupel P. Tumor hypoxia: definitions and current clinical, biologic, and molecular aspects. J Natl Cancer Inst 2001;93:266-76

139. Brown JM, Wilson WR. Exploiting tumour hypoxia in cancer treatment. Nat Rev Cancer 2004;4:437-47.

140. Wilson WR, Hay MP. Targeting hypoxia in cancer therapy. Nat Rev Cancer 2011;11:393-410.

141. Brown JM, Lemmon MJ. Potentiation by the hypoxic cytotoxin SR 4233 of cell killing produced by fractionated irradiation of mouse tumors. Cancer Res 1990;50:7745-9.

142. DiSilvestro PA, Ali S, Craighead PS, Lucci JA, Lee YC, Cohn DE, Spirtos NM, Tewari KS, Muller C, Gajewski WH, Steinhoff MM, Monk BJ. Phase III randomized trial of weekly cisplatin and irradiation versus cisplatin and tirapazamine and irradiation in stages IB2, IIA, IIB, IIIB, and IVA cervical carcinoma limited to the pelvis: a gynecologic oncology group study. J Clin Oncol 2014;32:458-64.

143. Duan JX, Jiao H, Kaizerman J, Stanton T, Evans JW, Lan L, Lorente G, Banica M, Jung D, Wang J, Ma H, Li X, Yang Z, Hoffman RM, Ammons WS, Hart CP, Matteucci M. Potent and highly selective hypoxia-activated achiral phosphoramidate mustards as anticancer drugs. $J$ Med Chem 2008;51:2412-20.

144. Borad MJ, Reddy SG, Bahary N, Uronis HE, Sigal D, Cohn AL, Schelman WR, Stephenson J Jr, Chiorean EG, Rosen PJ, Ulrich B, Dragovich T, Del Prete SA, Rarick M, Eng C, Kroll S, Ryan DP. Randomized phase II trial of gemcitabine plus TH-302 versus gemcitabine in patients with advanced pancreatic cancer. J Clin Oncol 2015;33:1475-81.

145. Townsend DM, He L, Hutchens S, Garrett TE, Pazoles CJ, Tew KD. NOV-002, a glutathione disulfide mimetic, as a modulator of cellular redox balance. Cancer Res 2008;68:2870-7.

146. Montero AJ, Diaz-Montero CM, Deutsch YE, Hurley J, Koniaris LG, Rumboldt T, Yasir S, Jorda M, Garret-Mayer E, Avisar E, Slingerland J, Silva O, Welsh C, Schuhwerk K, Seo P, Pegram MD, Gluck S. Phase 2 study of neoadjuvant treatment with NOV-002 in combination with doxorubicin and cyclophosphamide followed by docetaxel in patients with HER-2 negative clinical stage II-IIIc breast cancer. Breast Cancer Res Treat 2012;132:215-23.

147. Ishimoto T, Nagano O, Yae T, Tamada M, Motohara T, Oshima H, Oshima M, Ikeda T, Asaba R, Yagi H, Masuko T, Shimizu T, Ishikawa T, Kai K, Takahashi E, Imamura Y, Baba Y, Ohmura M, Suematsu M, Baba H, Saya H. CD44 variant regulates redox status in cancer cells by stabilizing the $\mathrm{xCT}$ subunit of system $\mathrm{xc}(-)$ and thereby promotes tumor growth. Cancer Cell 2011;19:387-400.

148. Lo M, Ling V, Low C, Wang YZ, Gout PW. Potential use of the anti-inflammatory drug, sulfasalazine, for targeted therapy of pancreatic cancer. Curr Oncol 2010;17:9-16.

149. Guan J, Lo M, Dockery P, Mahon S, Karp CM, Buckley AR, Lam S, Gout PW, Wang YZ. The xc- cystine/glutamate antiporter as a potential therapeutic target for small-cell lung cancer: use of sulfasalazine. Cancer Chemother Pharmacol 2009;64:463-72.

150. Wang JB, Erickson JW, Fuji R, Ramachandran S, Gao P, Dinavahi R, Wilson KF, Ambrosio AL, Dias SM, Dang CV, Cerione RA. Targeting mitochondrial glutaminase activity inhibits oncogenic transformation. Cancer Cell 2010;18:207-19. 